\title{
The Scope of Organizational Behavior Management: The Transformation from Internalization to Externalization
}

\author{
Jie ZHEN ${ }^{*}$ \\ East China University of Political Science and Law, Shanghai, China \\ jetzhen@163.com
}

Keywords: Organizational behavior management, Inward visualization, Externalization.

\begin{abstract}
The scope of organizational behavior management has always been constrained within the organization, which has its historical rationality. However, as a result of open innovation and the formation of network organization, the scope has transformed from the inside of the organization to the outside of the organization, which has exerted an important impact on the organizational performance.
\end{abstract}

\section{Introduction}

The boundary of the modern enterprise has been difficult to be defined by the property right relations because the inter-enterprises relations have been beyond the traditional enterprise boundaries on the breadth, depth and frequency. Therefore, inter-organizations relations and cooperative strategy should be viewed as an important perspective and content, and be absorbed and reflected in the process of behavior management through three levels: individual level, group level and organization level. Based on the analysis of the rationality of the inward visualization in organizational behavior management, this paper analyzes the inevitable trend of externalization, and then makes clear the scope of organizational behavior management transforming from the inside toward the outside.

\section{Historical Rationality of the Inward Visualization in Organization Behavior Management}

All the time, the behavior within the organization has been paid close attention. Take one enterprise as an example, the focus has been kept on the inside of the enterprise for a long time and the exploration of enhancing the production efficiency has been carried out in such a scope, which deal with the behavioral relations among the jobs or the departments.

Organizational behavior is a type of very complex social action, but in terms of behavioral content, it can be considered that organizational behavior includes two types: management behavior and business behavior. Among them, the management behavior is characterized by commanding others to accomplish specific tasks, such as the behaviors of company managers, school principals and directors of hospital, which are mainly centered on the activities of planning, organizing, leading and controlling. Business behavior is featured as accomplishing specific goal of the organization, such as workers manufacturing products, teachers giving lectures, doctors treating the disease, which is a specific business or operation and does not show up management attributes. Business behavior can make the organization directly achieve organizational objectives, while management behavior is the means and guarantee to promote business behavior to realize the organization's purpose.

Whether the organization's management behavior or business behavior, both of them show the complexity of organizational activities and have different angles to analyze and research the organizational behavior. It is generally believed that organizational behavior can be analyzed and studied from three levels which are individual level behavior from microcosmic perspective, group level behavior from medium view and organizational level behavior form macroscopic angle of view (see figure 1). The reason of studying organizational behavior based on the three levels is the inward visualization of the organization. Although this approach does not exclude the role of the 
external environment factors, there is no doubt that external factors has been ignored or marginalized.

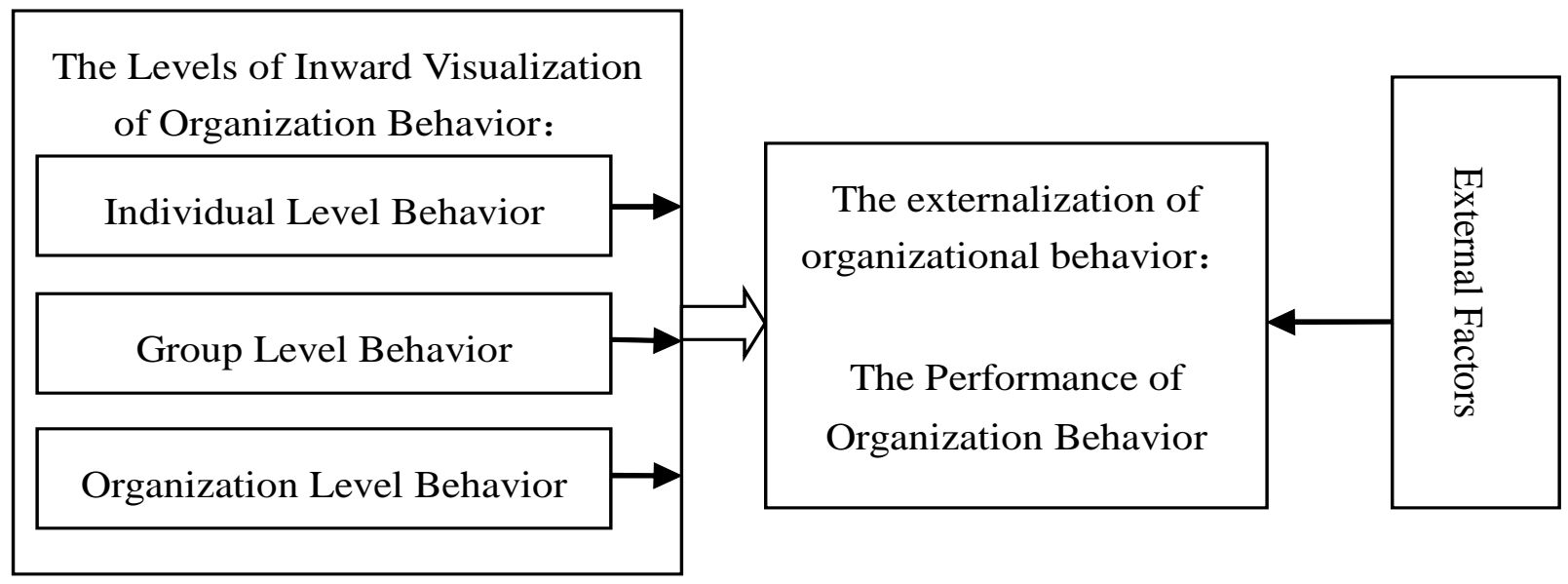

Fig 1. The Levels of Organizational Behavior in the Inward Visualization Perspective

\section{The Inevitable Trend of Externalization of Organization Behavior Management}

Under the new development background, technological innovation has become an urgent need for keeping economic sustainable development and enhancing national competitiveness, and is the core and key driving force for the survival and development of enterprises and other organizations. Taking the enterprise as an example, its technological innovation has undergone three stages, namely, the former innovation of simple introduction, the imitation innovation of integration improvement, and the independent innovation of research and development. At present, the fundamental cause of the research on the weakness of independent innovation is not the lack of research and development but the closed innovation model. Closed innovation emphasizes the key technical resources found within the enterprise and transforms the new ideas and new technology into new products through the enterprise's own channels of research and development, and then help the enterprise get values. Such innovation ideas are still the direct expression of the inward visualization within the organizational behavior management.

However, due to the destructive factors involving heavier and heavier availability and mobility of skilled workers, the development of venture capital market, the stalled research achievements facing more external opportunities and the production capacity of external suppliers keep improving, the development of enterprises will no longer depend entirely on their own internal plans and ideas but effectively utilize the ideas both inside and outside the enterprises. Thus, the enterprises emphasize the importance of external knowledge to the innovation process, that is, they should seek the approach of open innovation. [1] With this kind of innovation mode, it is bound to manage the organizations behavior more from the outside to achieve harmonious co-governance within and outside of the organizations.

At this time, the enterprises and other organizations form a specific network based on the competition relationship, and each organization occupies a different position in this network, which has the characteristics of identifiability and self-replication. In the organization network, enterprises discriminately occupy the corresponding resources and structurally allocate these resources according to their positions, and then make different contributions. From a static point of view, enterprises and other organizations need to pay attention to their behaviors from the outside (at least from the perspective of the network) and strive for favorable development position and space under the new development environment. While from a dynamic point of view, enterprises and other organizations must take appropriate organizational behavior to guide and promote the change of organizational behavior so as to optimize behavior performance (see figure 2). 


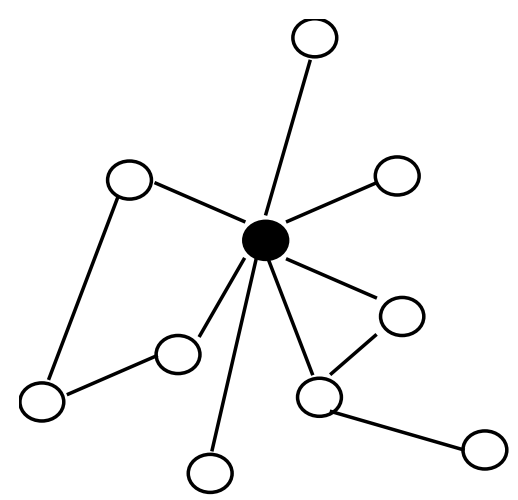

(a) The Organizational State of Centralization Tendency.

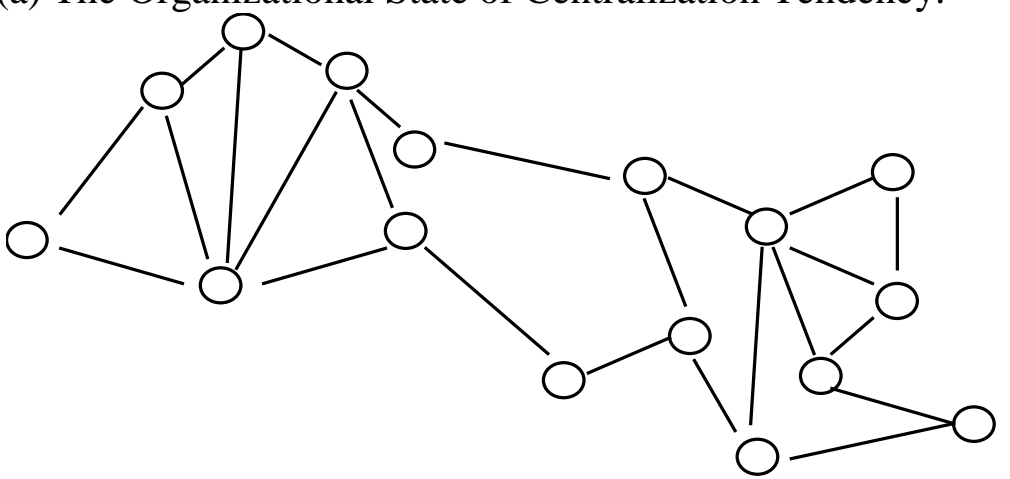

(b) The Organizational State of Decentralized Tendency

Fig 2. Network Development Environment to Promote the Externalized of Organizational Behavior

In general, figure 2 shows two kinds of commercial ecological network environment in the process of organizational survival and development, in which figure (a) signifies the organization in the network has a tendency to centralize and the black dot represents the organization at the core, while figure (b) denotes the decentralized organizational state. [2]

\section{The Scope of the Organization Behavior Management}

Organization behavior has systematically involved internal and external aspects. From the angle of the nature of management, management is about coordinating the internal and external relations, that is, effectively realizing the organization goals through harmonizing the relations among people-oriented posts, departments and the organization. This understanding befits the extension from the inside out of the scope of organization behavior management.

Organization behavior management is people-oriented, but the people in management are not abstract people in general sense, but the concrete ones with the position, department and organization as the carriers. Organizational behavior management is to coordinate the behavioral relationship of the persons who are embodied in these carriers which form six types of behavioral relations. The relations not only constitute the actual content of behavior management, but also delineate the historical path of the development of behavioral relations. The small squares in figure 3 represent these specific behavioral relation types, and the color of the squares gradually deepens and the direction of the arrow indicates the evolution tendency of behavioral relationship. We can analyze the organization behavior relationship from both inside and outside of the enterprise. 
Post Department Enterprise

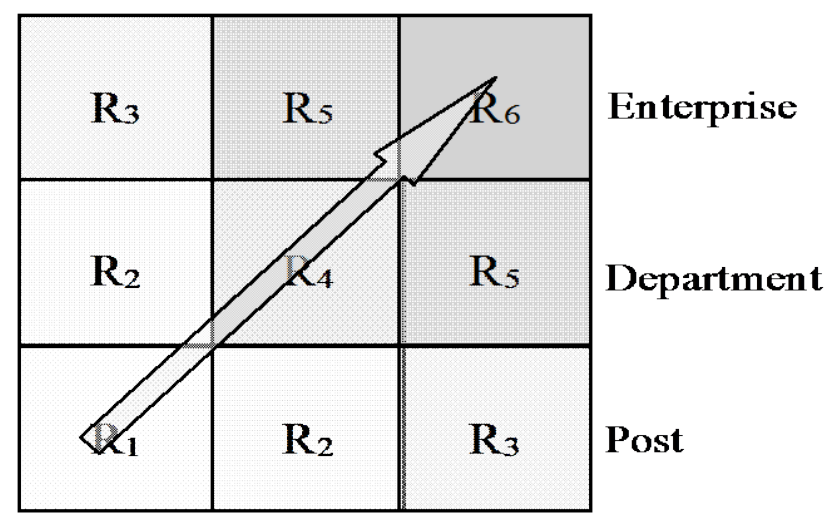

Fig 3. Matrix of Organization Behavior Management

\section{Internal Organization Behavior Management}

As shown in figure 3, the relations within enterprise include R1 (relationship between the posts), R2 (relationship between the posts and the departments), R3 (relationship between the posts and the enterprise), R4 (relationship between the departments), and R5 (relationship between the department and the enterprise). R1 appears in the process of distributing the work tasks and skill requirements among the different posts, and Taylor (1911) also pointed out that management is the measure of tasks, by which the work processes and systems are established. In fact, this is one of the methods to manage R1, R2 and R4 centering on the tasks or the skills. The modern enterprise reengineering theory is the fundamental rethinking and design of these behavioral relationships based on the logical method of the process. [3] R3 or R5 varies slightly depending on the ownership of the enterprise. In addition, Alfred p. Sloan Jr. divided the company into divisions by decentralization and preferred to conduct behavioral management of R4 and R5.

\section{External Organization Behavior Management}

The behavior management among the different organizations is shown by R6 in figure 3. At this point, the tentacle of organization behavior extends beyond the enterprise. Henry Mintzberg (1973) pointed out that the planners completely ignored the relationship network, talking to customers/suppliers and employees, the soft materials exerting intuition and secret message. While the shamrock organization structure put forward by Charles Handy is a form of organization which takes the managers and employees as the core and external contract workers and part-time workers as supplement. [4]

Overall, the development of organizational behavior management has been formed into a systematic state, which is transforming from focusing on internal behavior towards attaching equal importance to the internal and external behavior, and even more need to review the development situation of organization behavior from the outside of the organization. These two kinds of behavior process are not parallel or fragmented but mingling and mutual influencing each other through the historical accumulation and the economic and social development and evolution, which codetermine the organization behavior performance.

\section{Acknowledgement}

This research was financially supported by East China University of Political Science and Law under Grant 2017 Science Research Project, Shanghai Social Sciences Planning Project under Grant 2015JG009-BGL307 and the National Social Science Foundation of China under Grant 17BGL099. 


\section{References}

[1] Henry Chesbrough. Open Innovation: The New Imperative for Creating and Profiting from Technology. Harvard Business School Press, 2003.

[2] ZHEN Jie. Study on the Coordinating Mechanisms of Inter-Enterprises in the Innovation Cluster of Produce Services. Fudan University Press, 2012 (In Chinese).

[3] Michael Hammer, James A. Champy. Reengineering the Corporation: A Manifesto for Business Revolution, Harper Collins, 1993

[4] Charles Handy. The Age of Unreason. Random House Business, 1995. 